EDI TORI AL

\title{
En defensa del debate
}

\section{Defending the debate}

La libertad vive de respeto y la razón se nutre en la controversia.

José Martí (1888)

Se han formulado muy numerosos conceptos y definiciones de ciencia. Son afirmaciones frecuentes que la ciencia es forma de conciencia social, componente de la cultura, bien público, política, herramienta de trabajo y que se acerca a formar parte de la vida cotidiana.

Los que trabajan en el campo de la ciencia sí coinciden en reconocer que, para serlo, ha de regirse por los principios generales del método científico, identificado como el camino más eficiente para alcanzar un nuevo conocimiento. Y que estos principios generales se complementan con los propios de cada rama de la ciencia. Este método no se descubrió o se creó en un momento concreto, como un fármaco que revoluciona el tratamiento de una enfermedad; se desarrolló y consolidó en un período largo a cuyo perfeccionamiento contribuyeron decisivamente notables personalidades que vivieron entre los siglos XVI y Xx, tales como Descartes, Bernard, Marx, Einstein, Russell y Bunge.

Los avances científicos surgen del resultado de las investigaciones que se originan cuando el conocimiento común o experiencia empírica no encuentran solución a un problema que se necesita resolver, o cuando hace crisis un conocimiento aceptado que se muestra inconsistente ante nuevos hechos.

La duda, la critica a lo establecido, las discrepancias entre pensadores, la reflexión profunda sobre lo que provisionalmente damos por cierto, es el principal impulso para el progreso científico, es el núcleo de la creación científica. La ciencia sin debate no es ciencia, es dogma. Esta concepción preside la búsqueda de lo nuevo, para lo que tenemos un camino reconocido, el método científico, de cuya aplicación surgen debates que a su vez sugieren nuevos paradigmas y el abandono de otros.

Estas ideas son compartidas por la mayoría de los trabajadores de la ciencia, aunque ciertos grupos antagónicos las niegan en la práctica, algunos de los cuales incluso 
plantean que el método científico no es aplicable en el ámbito al que llaman de distinto modo, pero que en el campo de las ciencias médicas se conoce como "medicina alternativa". En casos extremos, llegan a considerar que la mejor prueba conocida y aceptada para valorar las posibles ventajas de un medicamento, el ensayo clínico controlado, no se puede aplicar para evaluar un producto natural (tales como las flores en el contexto de la llamada "terapia floral"), o un dispositivo (como las pirámides en su calidad de presunto agente terapéutico). Esta es la posición de la pseudociencia.

El presente número de la Revista Cubana de Salud Pública se produce a partir de la convocatoria a diversas personalidades de reconocido prestigio para que abordaran aspectos que consideraran polémicos en relación con el desempeño de nuestra disciplina. Se procuró abrir un espacio de intercambio y debate que, así lo deseamos, debe motivar a nuestros lectores a reflexionar sobre, disentir con o profundizar en las ideas aquí recogidas.

El efecto placebo es consecuencia de la relación entre la psiquis y el funcionamiento fisiológico y bioquímico del organismo. El conocimiento de estas relaciones permite conocer la importancia de factores sugestivos, como la confianza en el terapeuta o en el tratamiento utilizado debido a los resultados de las acciones sobre la enfermedad y el sujeto enfermo. Utilizar los conocimientos psicológicos que producen estos resultados positivos puede ser una contribución a una práctica médica más efectiva y humana, pero siempre sin apartarnos de una conducta ética rigurosa, en especial sin faltar a la verdad, ni ofrecer soluciones imposibles, ni crear imágenes públicas de nuevos logros científicos que no son tales. En los tiempos que corren, avalados por el reconocimiento de los aspectos positivos de la medicina natural, que usan los humanos desde hace milenios, a veces con efectos específicos, otra con efecto placebo, pero beneficiosos, no son pocos los fraudes y engaños que los inescrupulosos comerciantes encubiertos, practican a diario en todo el mundo y, ciertamente, también en Cuba. De ahí que el primer artículo que se pone a consideración del lector aborde con rigor este tema.

Se han obtenido progresos notables en la calidad de las evidencias científicas que avalan las intervenciones en materia de salud. Estas intervenciones, especialmente en el marco de la atención individual, se evalúan principalmente mediante ensayos clínicos controlados y aleatorizados. Sus principios, métodos y procedimientos están claramente definidos, se posee buena experiencia en el país, donde existen instituciones que los regulan y supervisan. No hay excusa alguna que justifique la omisión de estas normas en determinados casos. También se conocen sus limitaciones, que no descalifican estos ensayos como la más poderosa herramienta disponible para la evaluación de medicamentos, vacunas u otros medios terapéuticos o diagnósticos. Junto con esta problemática, uno de los autores intenta esclarecer el papel del movimiento que ha dado en llamarse "Medicina basada en la evidencia", en buena medida vertebrada, precisamente, en torno a los ensayos clínicos, pero a su vez, dependiente de que la información disponible no padezca sesgos importantes por razones de inclusión en las fuentes de que aquella se nutre, otro de los temas abordados. La calidad de la literatura que se produce y las reglas para sacar conclusiones de naturaleza causal, que se inscriben en esta misma órbita, también son objeto de reflexión.

La ciencia es también noticia cotidiana. Los medios masivos de información se ocupan de difundir los nuevos descubrimientos o avances tecnológicos. Un campo de particular atención de esos medios es el de la salud. Esto contribuye favorablemente a los propósitos de la salud pública, pero también puede ocasionar graves perjuicios al propio sistema de salud y a la sociedad. Difundir falsos resultados, exagerar su trascendencia, promover falsas esperanzas son hechos observados con cierta frecuencia. En ocasiones son engaños deliberados de profesionales faltos de ética; 
otras veces, malas prácticas del periodismo científico. En ambos casos se impone incrementar la cultura científica tanto de los periodistas como de quienes constituyen sus fuentes de información. I gualmente relacionados con aspectos sociales y casi siempre con implicaciones éticas- se hallan otras perniciosas tendencias, tales como desdeñar el papel de la intersectorialidad como forma de abordaje de los problemas, medicalizar la salud pública, omitir los enfoques de género en análisis que lo requieren y desatender los determinantes sociales de la salud. Todos estos temas han sido incluidos en el presente número.

Finalmente, nuestra revista reconoce a través de respectivos trabajos, la importancia cardinal de la investigación, el papel del análisis económico, los desarrollos en materia biotecnológica y la irrupción de Internet como zonas que exigen atención y desarrollo en nuestro sistema de salud.

A fijar posiciones y dejar claro de qué lado debemos estar, se dedican las páginas de este número extraordinario de nuestra revista. Con la generosa aceptación a nuestra invitación por parte de 24 especialistas, tanto cubanos como extranjeros, todos ellos poseedores de grado científico, hemos podido conformar esta revista, con la cual aspiramos contribuir al fortalecimiento del nivel científico y ético de los profesionales de la salud.

Profesor Francisco Rojas Ochoa 